\title{
The exon junction complex controls transposable element activity by ensuring faithful splicing of the piwi transcript
}

\author{
Colin D. Malone, ${ }^{1,2,5}$ Claire Mestdagh, ${ }^{3,5}$ Junaid Akhtar, ${ }^{3}$ Nastasja Kreim, ${ }^{3}$ Pia Deinhard, ${ }^{3}$ \\ Ravi Sachidanandam, ${ }^{4}$ Jessica Treisman, ${ }^{1}$ and Jean-Yves Roignant ${ }^{3}$ \\ ${ }^{1}$ Kimmel Center for Biology and Medicine at the Skirball Institute of Biomolecular Medicine, Department of Cell Biology, New \\ York University School of Medicine, New York, New York 10016, USA; ${ }^{2}$ Howard Hughes Medical Institute, ${ }^{3}$ Institute of \\ Molecular Biology (IMB), 55128 Mainz, Germany; ${ }^{4}$ Department of Oncological Sciences, Icahn School of Medicine at Mount \\ Sinai, New York, New York 10029, USA
}

The exon junction complex (EJC) is a highly conserved ribonucleoprotein complex that binds RNAs during splicing and remains associated with them following export to the cytoplasm. While the role of this complex in mRNA localization, translation, and degradation has been well characterized, its mechanism of action in splicing a subset of Drosophila and human transcripts remains to be elucidated. Here, we describe a novel function for the EJC and its splicing subunit, RnpS1, in preventing transposon accumulation in both Drosophila germline and surrounding somatic follicle cells. This function is mediated specifically through the control of piwi transcript splicing, where, in the absence of RnpS1, the fourth intron of piwi is retained. This intron contains a weak polypyrimidine tract that is sufficient to confer dependence on RnpS1. Finally, we demonstrate that RnpS1-dependent removal of this intron requires splicing of the flanking introns, suggesting a model in which the EJC facilitates the splicing of weak introns following its initial deposition at adjacent exon junctions. These data demonstrate a novel role for the EJC in regulating piwi intron excision and provide a mechanism for its function during splicing.

[Keywords: EJC; splicing; transposon; piRNA; Piwi; AGO3]

Supplemental material is available for this article.

Received May 19, 2014; revised version accepted July 15, 2014.

mRNA maturation requires pre-mRNA splicing, a process that removes introns from primary transcripts and subsequently ligates adjacent exons. Splicing plays essential roles during development, and its alteration is linked to a variety of diseases, including cancer (Srebrow and Kornblihtt 2006; Orengo and Cooper 2007; Baralle et al. 2009; David and Manley 2010). Cis-regulatory sequences within introns and exons regulate splicing by recruiting the spliceosome and associated factors to the primary transcript. Other layers of regulation, such as the influence of chromatin and transcription complexes, can also impact the splicing process (for review, see Long and Caceres 2009; Luco et al. 2011; Braunschweig et al. 2013; De Conti et al. 2013; Iannone and Valcarcel 2013). Despite considerable progress, the understanding of how the spliceosome successfully recognizes and precisely excises diverse introns in a variety of pre-mRNA molecules remains a challenge.

\footnotetext{
${ }^{5}$ These authors contributed equally to this work. Corresponding author: j.roignant@imb-mainz.de

Article published online ahead of print. Article and publication date are online at http://www.genesdev.org/cgi/doi/10.1101/gad.245829.114.
}

A critical link between pre-mRNA splicing and cytoplasmic functions was elucidated with the discovery of the exon junction complex (EJC) (Le Hir et al. 2000). This ribonucleoprotein complex is deposited onto mRNA 20-24 nucleotides (nt) upstream of exon-exon junctions as a consequence of splicing and remains stably associated during nuclear export to influence subsequent post-transcriptional events. In human cells, the EJC is associated with the majority of exon junctions, and its binding is linked to the adjacent binding of other mRNP components such as serine/arginine-rich (SR) proteins (Sauliere et al. 2012; Singh et al. 2012). The core of the EJC is composed of four proteins. The DEAD-box RNA helicase eIF4AIII directly binds to the RNA and is recruited early in the splicing reaction via its interaction with the spliceosome component CWC22 (Shibuya et al. 2004; Alexandrov et al. 2012; Barbosa et al. 2012; Steckelberg et al. 2012). Mago nashi

(C) 2014 Malone et al. This article is distributed exclusively by Cold Spring Harbor Laboratory Press for the first six months after the full-issue publication date (see http://genesdev.cshlp.org/site/misc/terms.xhtml). After six months, it is available under a Creative Commons License (Attribution-NonCommercial 4.0 International), as described at http:// creativecommons.org/licenses/by-nc/4.0/. 
(Mago) and Tsunagi (Tsu/Y14) are recruited later during excision of the lariat intron and exon joining to lock the complex onto RNA by inhibiting the ATPase activity of eIF4AIII (Ballut et al. 2005). These three subunits constitute the pre-EJC. In the cytoplasm, the addition of Barentsz (Btz) completes the core EJC and further stabilizes association with the RNA (Bono et al. 2006; Gehring et al. 2009; Bono and Gehring 2011). Numerous other proteins interact transiently with the EJC to mediate additional posttranscriptional functions (Tange et al. 2005).

Despite the association of the EJC with most spliced RNAs, much work has shown its involvement in specific and distinct functions in vivo. For instance, both Mago and Tsu are required for dorsal-ventral axis formation in the Drosophila egg chamber (Micklem et al. 1997; Newmark et al. 1997; Hachet and Ephrussi 2001; Mohr et al. 2001) and affect earlier processes in oogenesis, such as germline stem cell (GSC) differentiation and oocyte specification (Parma et al. 2007). In vertebrates, reduction of mago affects neural stem cell division and melanoblast development (Silver et al. 2010, 2013). Finally, the three pre-EJC subunits are required for photoreceptor differentiation in flies (Ashton-Beaucage et al. 2010; Roignant and Treisman 2010). Investigation of this function revealed that the pre-EJC is necessary for splicing $M A P K$ and other transcripts that contain long introns and are expressed from heterochromatic loci. Why these features create a requirement for the pre-EJC is currently not understood. Other studies recently found a role for the EJC in controlling the alternative splicing of the proapoptotic regulator Bcl-x in human cancer cells and the splicing of the ryanodine receptor in Xenopus (Haremaki and Weinstein 2012; Michelle et al. 2012). Since the EJC joins the spliceosome at a late step in the splicing reaction, it remains unclear whether it can directly regulate splicing and, if so, by what mechanism.

In order to gain mechanistic insight into the role of the EJC in the splicing process, we set out to look for additional EJC targets. As mentioned, the EJC plays an important role in controlling axis polarity in Drosophila, as mago mutants lay ventralized embryos (Micklem et al. 1997; Newmark et al. 1997). Intriguingly, a similar defect is caused by impairment of the small RNA-based Piwiinteracting RNA (piRNA) pathway, suggesting a potential role for the EJC in piRNA production or function (Theurkauf et al. 2006). The piRNA pathway is an evolutionarily conserved RNAi system that acts predominantly in gonads to suppress the activity of transposable elements (Sarot et al. 2004; Malone et al. 2009). In flies, many piRNAs are derived from long precursors expressed from heterochromatic loci termed "piRNA clusters." piRNA clusters are densely packed with transposable elements, often fragmented and no longer active, which produce precursor RNAs that give rise to piRNAs capable of targeting active transposons. piRNAs are loaded into three distinct Argonaute proteins of the PIWI clade: Piwi, Aubergine (Aub), and AGO3 (for review, see Carmell et al. 2002). Piwi is predominantly nuclear and is required in both germline and surrounding somatic follicle cells to guide transcriptional silencing via heterochromatin for- mation (Cox et al. 1998, 2000; Megosh et al. 2006; Sienski et al. 2012; Le Thomas et al. 2013; Rozhkov et al. 2013). In contrast, Aub and AGO3 are germline-specific and enriched in a perinuclear structure termed "nuage" (Wilson et al. 1996; Harris and Macdonald 2001; Brennecke et al. 2007; Nishida et al. 2007; Nagao et al. 2010). Aub and AGO3 are targeted to cleave transposon or piRNA precursor transcripts, respectively, via their slicer activity. This reciprocal cleavage and subsequent processing amplifies piRNA production and intensifies the germline silencing response in what is called the "ping pong" cycle (Brennecke et al. 2007; Gunawardane et al. 2007; Senti and Brennecke 2010).

In this study, we found that the EJC inhibits transposon activity in both ovarian germline and follicle cells. The cytoplasmic subunit Btz is not involved, implying a nuclear function. Consistent with this, we found that the level of piwi transcript is reduced in the absence of the preEJC or of the accessory splicing subunit RnpS1 and its cofactor, Acinus (Acn). Although piwi is a euchromatic gene without large introns, the splicing of its fourth intron is impaired without the pre-EJC. We found that the main determinant of its retention upon EJC depletion was the presence of a weak polypyrimidine tract (PPT). We further demonstrate that excision of the piwi fourth intron requires prior splicing of the flanking introns. This suggests a model in which splicing of strong introns allows deposition of the EJC at their exon junctions, which facilitates the subsequent removal of the adjacent intron that contains a poorly defined PPT. In addition to demonstrating its novel function in the piRNA pathway via piwi splicing, these results imply that the EJC may play a more general role in determining the kinetics of intron excision.

\section{Results}

The EJC prevents transposon derepression in both germline and follicle cells

To investigate a possible role of the EJC in the piRNA pathway, we took advantage of dsRNA constructs from the Vienna Drosophila Resource Center (VDRC) and Transgenic RNAi Project (TRiP) collections to specifically knock down individual EJC components. We first confirmed the functionality of these constructs by driving their expression in larval eye discs using the eyeless (ey)-GAL4 driver. Expression of mago dsRNA or tsu dsRNA in the eye recapitulated the phenotypes observed with the loss-offunction mutant alleles, although their effects were weaker (Supplemental Fig. S1). In addition, expression of btz dsRNA had no effect on photoreceptor differentiation, consistent with the normal development of eye disc cells homozygous for the $b t z^{2}$ loss-of-function allele (Supplemental Fig. S1). Expression of eIF4AIII dsRNA was celllethal, preventing further analysis (data not shown). We therefore expressed dsRNA targeting the other three subunits in either germline or surrounding follicle cells (using nanos [nos]-GAL4 or traffic jam [ti]-GAL4 drivers, respectively) (Fig. 1A) and examined the levels of representative transposons and ovarian morphology.

Somatic knockdown (SKD) of mago and, to a lesser extent, tsu in follicle cells gave rise to rudimentary 
A

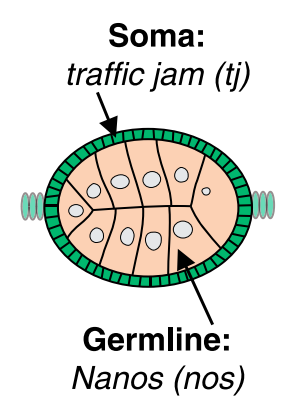

C

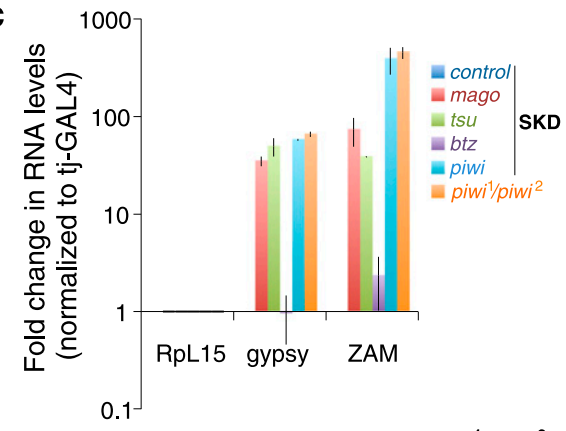

C

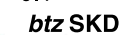

B Control mago SKD
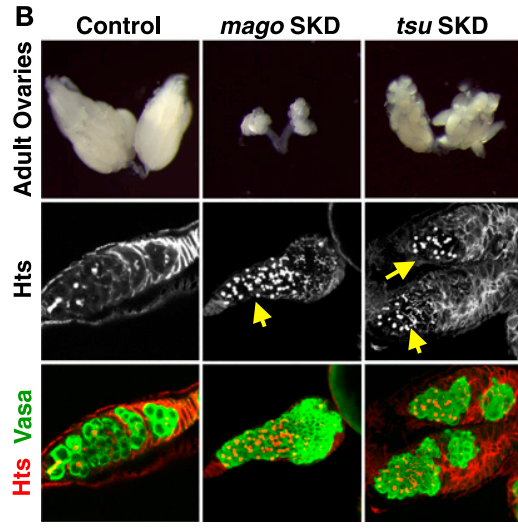

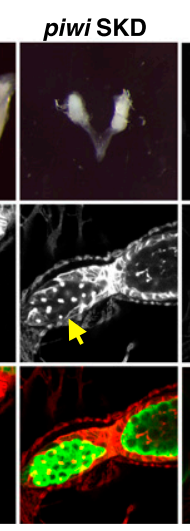

piwi $^{1} /$ piwi $^{2}$

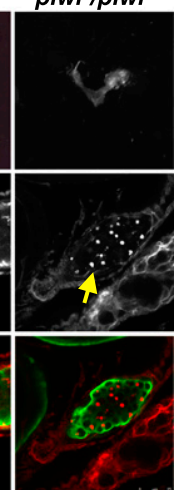

Figure 1. The pre-EJC prevents transposon mobilization in the Drosophila ovary. $(A)$ Schematic representation of an egg chamber showing somatic (traffic jam) and germline (nanos) cells. (B) Adult ovaries from the indicated genotypes were stained with anti-Hts (red) and anti-Vasa (green) and show extra stem cells (yellow arrows). (SKD) Somatic knockdown. (C) qRT-PCR of gypsy and ZAM in ovarian samples depleted for EJC subunits in follicle cells. piwi mutant ovaries (orange) are shown as a control. ovaries, which were devoid of mature egg chambers (Fig. 1B). In these knockdown ovaries, follicle cells formed multicellular layers and failed to encapsulate developing egg chambers, similar to piwi knockdown and loss of function (Fig. 1B; Jin et al. 2013). To gain insight into these developmental defects, we stained ovaries with the Hts antibody, which marks the spectrosome and cell cortex. The spectrosome is a spherical, germline-specific organelle found in GSCs, and as cystoblasts differentiate, it becomes increasingly branched to form the fusome. In wild-type ovaries, spectrosomes are present in the two or three stem cells at the tip of the germarium. Ovaries with follicle cells depleted of mago and tsu showed an increase in the number of spectrosome-like structures, indicating an accumulation of GSCs that had failed to differentiate (Fig. 1B). This is reminiscent of the GSC tumor-like phenotype of piwi loss of function (Fig. 1B; Jin et al. 2013). In contrast, depletion of $b t z$ had no effect on either morphology or GSC differentiation.

Given the similarity of mago and tsu knockdown phenotypes to that of piwi, we tested whether the transposon silencing defects observed in the absence of piwi (Sarot et al. 2004) are similarly induced by EJC depletion. Activity of the retrotransposons gypsy and ZAM is restricted to follicle cells, and their proliferation is inhibited by the piRNA pathway. We found that, upon SKD of mago and tsu, like piwi, the levels of gypsy and $Z A M$ RNA increased dramatically, while btz SKD had no effect (Fig. 1C; Supplemental Fig. S2A). Germline knockdowns (GLKDs) of mago and tsu also displayed significant derepression of the predominant germline transposons HeT-A, GATE, and Burdock, which again remained unchanged upon btz depletion (Supplemental
Fig. S2B,C). Loss of mago and tsu led to a marked increase in dsDNA breaks (Klattenhoff et al. 2007), supporting their role in protecting the genome from transposon mobilization (Supplemental Fig. S2D). These results indicate that the core nuclear components of the EJC are required for GSC differentiation and ensure the competency of the piRNA pathway to regulate transposons in both germline and somatic cells of the ovary.

\section{The EJC controls the level of Piwi protein}

Defects in the piRNA pathway often lead to a mislocalization and/or reduction in the level of Piwi-clade Argonaute proteins (Malone et al. 2009; Olivieri et al. 2010). In fact, piRNA pathway factors have been categorized based on their effects on the localization pattern of Argonaute proteins and whether they preferentially alter primary (Piwi) or secondary (Aub and AGO3) piRNA biogenesis or both (Olivieri et al. 2012).

To confirm that the pre-EJC regulates transposon expression by promoting the activity of the piRNA pathway, we assessed Piwi-clade protein localization in several EJC mutant contexts. In mago- and tsu-null mutant clones, the levels of AGO3 and Aub did not appear significantly changed (Fig. 2A,B; Supplemental Fig. S2E). However, these proteins appeared to partially relocalize to cytoplasmic bodies, suggesting that the integrity of nuage or their localization to this structure was disturbed. In contrast, we observed a significant decrease of Piwi levels in both germline and somatic clones of both mago and tsu (Fig. 2C; Supplemental Fig. $\mathrm{S} 2 \mathrm{E})$. Collectively, these results indicate that the pre-EJC 
A

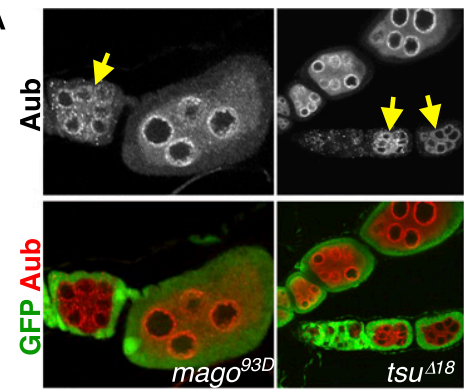

C Germline Clones
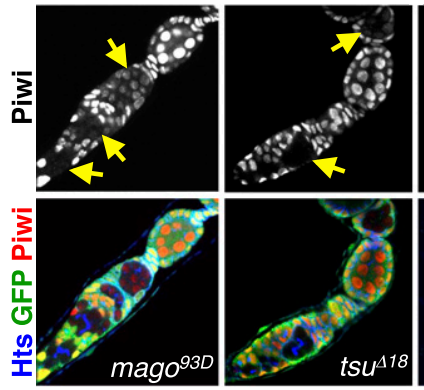

B
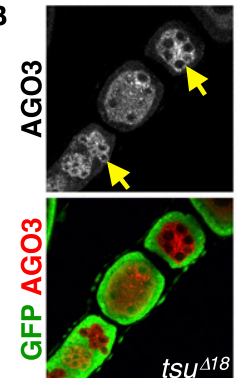

Somatic clones

Figure 2. The pre-EJC specifically controls Piwi levels. $(A-C)$ Ovaries containing clones homozygous for the Y14-null allele $t s u^{\Delta 18}$ or for the mago loss-of-function allele $\left(\right.$ mago $\left.^{93 D}\right)$ are marked by the absence of GFP (green; yellow arrows) and were stained with antibodies against $\mathrm{Aub}(A), \mathrm{AGO}(B)$, or Piwi (red) and Hts (blue) $(C)$.

is required for normal Piwi levels but has only a minor effect on AGO3 and Aub localization.

Loss of the splicing subunit RnpS1 recapitulates EJC core subunit phenotypes

Since knockdown of cytoplasmic Btz has no impact on transposon levels, the pre-EJC is likely to regulate the piRNA pathway through a nuclear mechanism. Two nuclear functions have previously been proposed for the preEJC: one in splicing (Ashton-Beaucage et al. 2010; Roignant and Treisman 2010; Michelle et al. 2012) and one in the control of mRNA export (Le Hir et al. 2001; Gatfield and Izaurralde 2002; Shiimori et al. 2013). In order to investigate which post-transcriptional function of the EJC was involved in the piRNA pathway, we knocked down a representative set of EJC accessory factors and analyzed both Piwi and transposon levels. Interestingly, we found that depletion of the splicing subunit RnpS1 reduced Piwi levels in both follicle and germline cells (Fig. 3A,B). This effect was further confirmed by Western blot analysis (Supplemental Fig. S3A). In contrast, knocking down the export factor Aly/Ref1 had no impact on Piwi, while an additional RnpS1 cofactor, Acinus (Acn), was also required (Fig. 3A; Supplemental Fig. S4A). Interestingly, other direct RnpS1 partners, including Sin3-associated 18-kDa protein (SAP18) and Pinin, were not required for Piwi protein accumulation and localization (Fig. 3A).

To further characterize the role of RnpS1 in the piRNA pathway, we investigated the effect of its knockdown on transposon levels using several complementary approaches. First, we drove expression of dsRNA targeting

RnpS1 in either germline or follicle cells in the presence of Burdock-GFP or Gypsy-LacZ transposon reporters, respectively (Handler et al. 2013). While no signal was detected in control ovaries, clear expression was observed in both cell types upon RnpS1 knockdown (Supplemental Fig. S3B). Second, we performed quantitative RT-PCR (qRT-PCR) and observed that, upon depletion of RnpS1, both germline and somatic transposons were strongly derepressed in their respective tissues (Supplemental Fig. S3C,D). Finally, we took a genome-wide approach to obtain a comprehensive view of the impact of RnpS1 knockdown on the level of transposons. Total RNAs derived from either control or RnpS1 knockdown ovaries (in both germline and follicle cells) were depleted of ribosomal RNAs, cloned, and sequenced. We confirmed that many transposons were significantly up-regulated upon RnpS1 depletion. All classes of elements, which include those predominantly expressed in the soma (Idefix) or germ cells (HeT-A and GATE), showed increased expression (Fig. 3C-E). Altogether, these results indicate that $\mathrm{RnpS1}$ is required to silence transposons and acts similarly to core piRNA pathway components (Czech et al. 2013).

\section{EJC depletion and loss of Piwi have similar effects on small RNA profiles}

Since loss of Piwi-clade proteins can lead to dramatic and specific alterations in piRNA populations (Malone et al. 2009), we sought to investigate whether EJC disruption also affects small RNA levels. We profiled small RNAs from control, mago, and RnpS1 tissue-specific knockdown ovaries and analyzed small RNA production from piRNA clusters. For both mago and RnpS1, GLKD preferentially reduced piRNAs from the germline-specific $42 \mathrm{AB}$ cluster, while SKD reduced piRNA expression from the soma-specific flamenco cluster (Fig. 3F). An expanded analysis revealed that mago and RnpS1 GLKDs reduced piRNAs from all germline clusters, similar to piwi, while another somatic cluster from the ti 3' untranslated region (UTR) was unaffected or even slightly increased (Fig. 3G). Conversely, SKD reduced flamenco and $t j$ piRNAs, leaving germline clusters mostly unaffected (Fig. 3G). These results indicate that nuclear components of the EJC are required for either piRNA production or stability.

Since piRNAs are essential for germline transposon regulation, we looked for effects on the levels and patterns of piRNAs that target transposons. As with piRNA clusters, transposable elements display preferential expression in either germline or somatic tissues (Brennecke et al. 2008). After sorting transposons by class and piRNA abundance, we assessed whether piRNAs that mapped to these transposons were capable of engaging in germline ping-pong, a signature of Aub and AGO3 function. Our data indicate that Aub and AGO3 remain engaged in ping-pong to regulate transposon expression during RnpS1 GLKD despite an overall reduction in piRNA levels (Supplemental Fig. S3F). mago knockdown reduced transposon targeting piRNAs to an extent similar to or even more severely than 


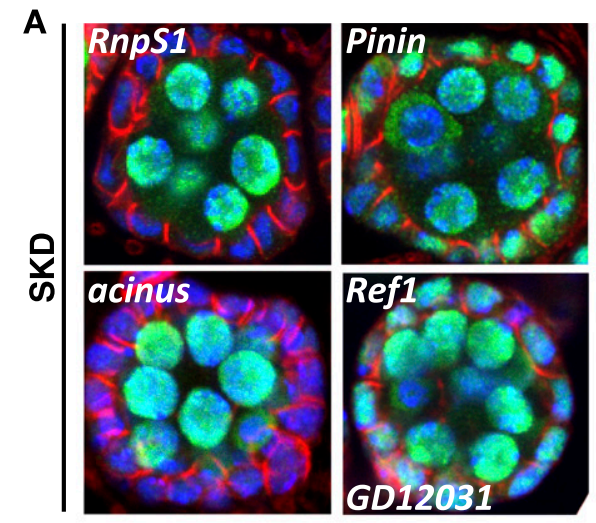

C

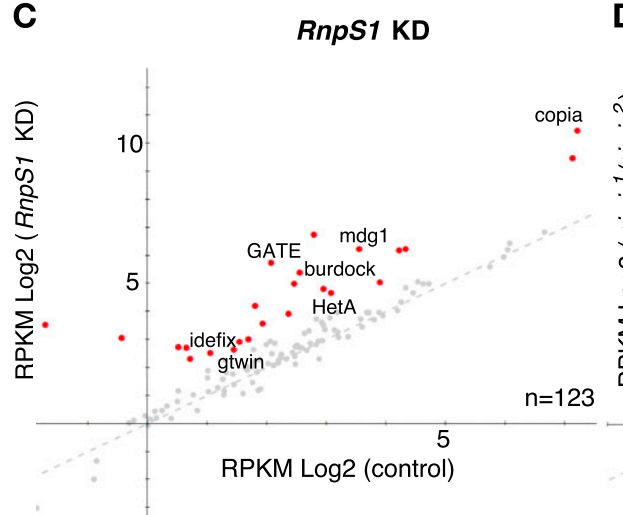

$\mathbf{F}$

F position on chr 2R (Mbp) Control

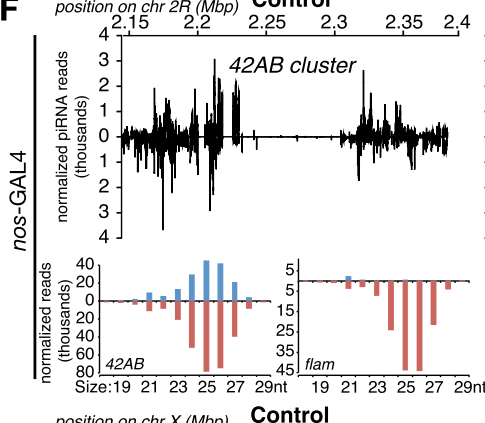

position on chr $X$ (Mbp) Control
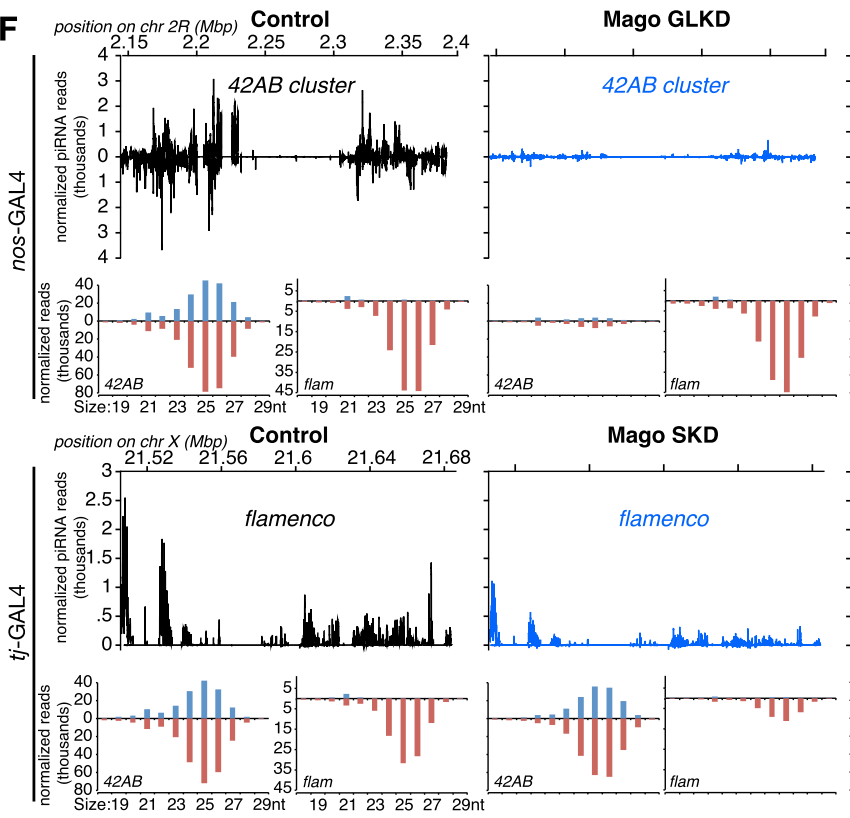

Mago SKD

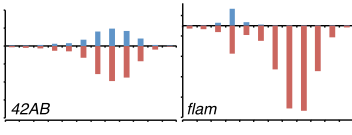

RnpS1 SKD
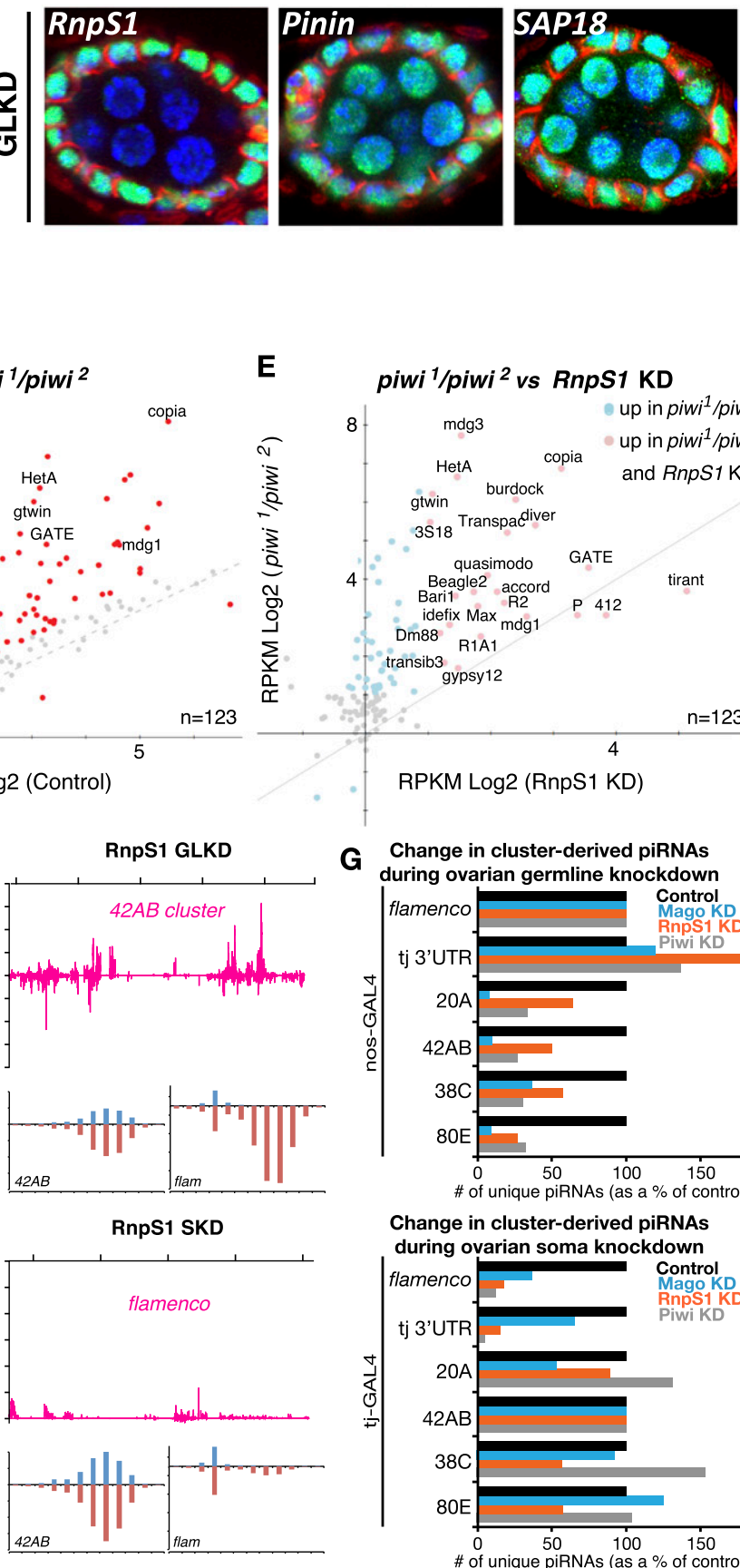

E

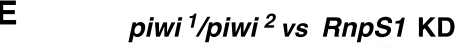
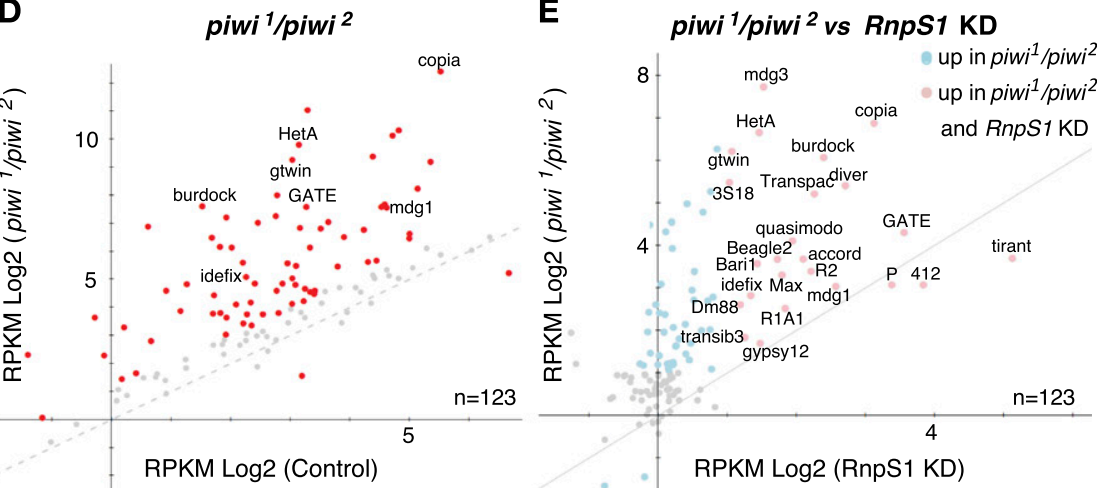

RPKM Log2 (RnpS1 KD)

G Change in cluster-derived piRNAs during ovarian germline knockdown

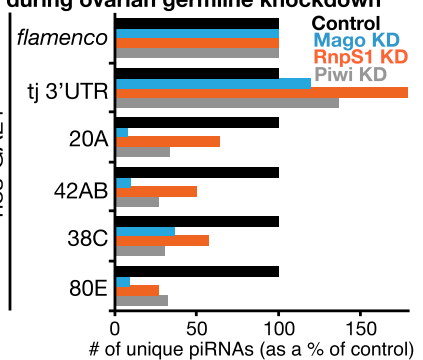

Change in cluster-derived piRNAs during ovarian soma knockdown

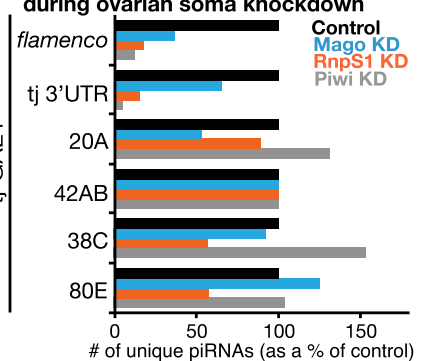

Figure 3. The EJC accessory subunit RnpS1 is required for Piwi accumulation and transposon regulation. $(A, B)$ Egg chambers stained for Piwi (green), Hts (red), and DNA (blue) during SKD $(A)$ or GLKD $(B)$ of RnpS1 and accessory factors. $(C-E)$ Twofold or greater, statistically significant transposon derepression (red and blue) in RnpS1 knockdown and piwi mutant ovaries compared with controls and each other. No transposons showed a more than twofold change only in RnpS1 knockdown. (F) Unique small RNA mapping and size distribution over canonical germline (42AB) and somatic (flamenco) piRNA clusters in ovaries with EJC component knockdowns. $(G)$ Normalized representation of cluster piRNA levels in mago (blue), RnpS1 (orange), and piwi (gray) knockdown ovaries.

RnpS1, which could explain its stronger morphological phenotype. In conclusion, the fact that ping-pong remains intact indicates that secondary piRNA biogenesis is not wholly dependent on the EJC. Our results support an essential role for the EJC in the Piwi-dependent primary piRNA pathway. 
RnpS1 is required to facilitate piwi transcript splicing

A failure to load small RNAs into Piwi triggers a defect in Piwi nuclear accumulation and its subsequent destabilization (Olivieri et al. 2010, 2012). Therefore, the observed decrease in Piwi levels during RnpS1 depletion could be an indirect consequence of diminished piRNA levels. Alternatively, since the EJC plays critical roles in mRNA metabolism, a more direct effect on piwi RNA processing is also plausible. To distinguish between these possibilities, we examined piwi mRNA levels by qRT-PCR using several amplicons spanning the transcript. Interestingly, we found that RnpS1-depleted ovaries showed a $40 \%-80 \%$ decrease in piwi transcript levels (Fig. 4A), with the strongest effect observed on the amplicon spanning exons 4 and 5 . We confirmed that piwi transcript levels were also reduced by mago GLKD using RNA fluorescent in situ hybridization (FISH) (Fig. 4B). This effect appears specific, since, of 20 validated components of the piRNA pathway, only piwi mRNA (and, to a lesser extent, AGO3) displayed a significant decrease upon RnpS1 knockdown (SKD and GLKD) (Supplemental Fig. S5A). Further qRT-PCR displayed a significant increase in $A G O 3$ intron retention, indicating partial dependence on the EJC for efficient transcript processing (Supplemental Fig. S6). This may relate to the previously described function of the EJC in regulating large heterochromatic genes.
To search for additional piRNA pathway genes targeted by the EJC, we used our RNA sequencing (RNA-seq) data to compare the expression in control versus RnpS1 knockdown ovaries of all genes identified in three screens for regulators of the piRNA pathway (Czech et al. 2013; Handler et al. 2013; Muerdter et al. 2013). In total, 467 genes were examined, and we found that five in addition to piwi showed a decrease in expression of at least 1.5-fold (Supplemental Fig. S5B). Of these candidates, piwi was most strongly down-regulated, suggesting that piwi is the main target of RnpS1 in the piRNA pathway. To further confirm this hypothesis, we compared the genome-wide changes of transposon levels in RnpS1 knockdown ovaries with those of piwi mutant ovaries. Piwi regulates only a subset of transposons, so derepression of these transposons provides a clear signature of its effect. Strikingly, while the effect on transposon levels was stronger in piwi mutant ovaries (Fig. 3C,D), every transposon up-regulated in RnpS1 knockdown ovaries was also up-regulated in piwi mutants (Fig. 3E). These results indicate that piwi reduction is partially sufficient to explain the effects of RnpS1 on the piRNA pathway.

To test whether the EJC regulates piwi transcriptionally or post-transcriptionally, we took advantage of an enhancer trap $\mathrm{P}$ element inserted in the first intron of piwi that expresses lacZ under piwi regulatory sequences (Lin and Spradling 1997). In tsu mutant clones, lacZ levels were not
A

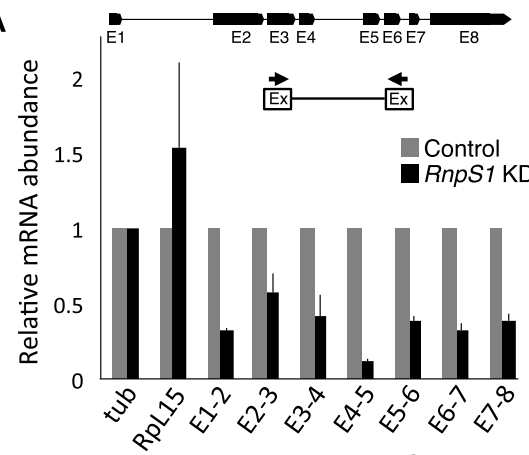

B

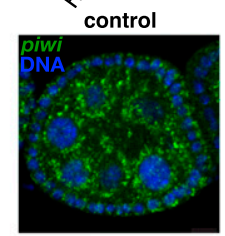

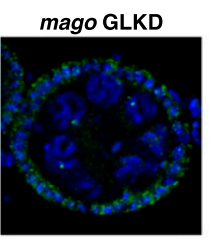

D

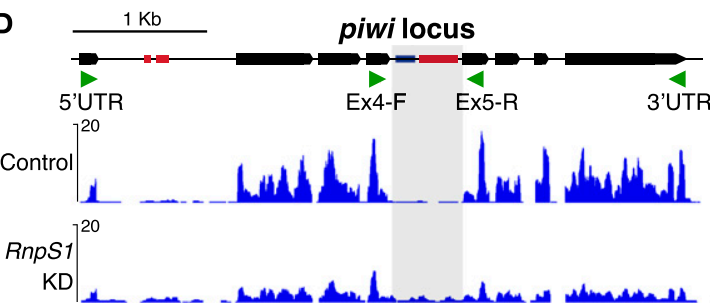

E

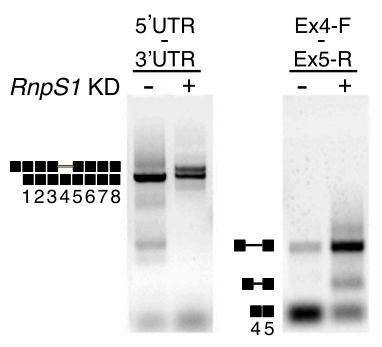

$\mathbf{F}$

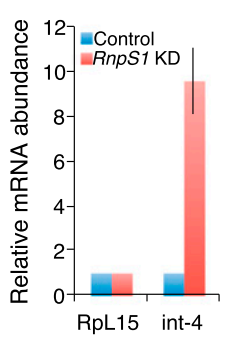

C

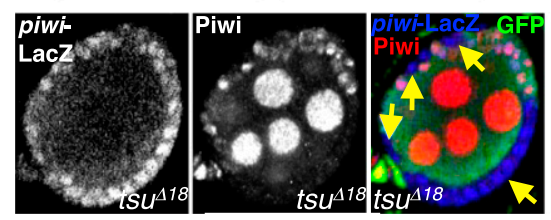

Figure 4. Efficient splicing of the piwi fourth intron is dependent on the EJC. $(A)$ qRT-PCR spanning each exon (E) junction of the piwi transcript, normalized to tubulin, and with RpL15 as a control. (B) piwi transcripts are visualized using RNA FISH in control and mago GLKD egg chambers (green). (C) Assessment of piwi transcription using a LacZ reporter (blue) in tsu mutant somatic clones marked by a lack of GFP (green; yellow arrows). Piwi protein is stained in red. (D) RNA transcript mapping over the piwi locus from control and RnpS1 knockdown ovaries. Intronic transposons Cr1A (blue) and DINE (red) and intron read accumulation (gray box) are shown. (E) RT-PCR of full-length piwi and intron 4 (primers shown by green arrows in $D$ ) with and without RnpS1 knockdown. (F) Quantification by RT-PCR of piwi fourth intron retention. 
decreased, suggesting that EJC loss does not reduce piwi transcription (Fig. 4C).

We then sought to investigate whether piwi splicing remained intact. Using the RnpS1 knockdown RNA-seq data, we observed a general decrease in the number of reads mapping to piwi exons, which is consistent with the reduction detected by qPCR and immunofluorescence. In contrast, the number of reads mapping to intron 4 was significantly increased, indicating an accumulation of this intron in the absence of RnpS1 (Fig. 4D). To confirm these observations, primers spanning the entire transcript as well as each exon-exon junction were used to amplify piwi from wild-type and RnpS1-depleted ovarian RNA. We detected a major defect in the splicing of the fourth intron (Fig. 4E), leading to a dramatic accumulation of unspliced RNA (Fig. 4F). Interestingly, we also observed some retention of this intron in the wild-type condition, indicating that the intron is normally inefficiently spliced. Furthermore, we found a less striking defect in the splicing of the first intron, where activation of a cryptic splice site occurs in wild-type ovaries at a low level and more frequently in RnpS1 knockdown conditions (Fig. 4D; data not shown). Thus, these data show that piwi intron 4 and, to a lesser extent, intron 1 are suboptimally spliced under normal conditions and that RnpS1 and the EJC must support efficient transcript splicing in order to maintain Piwi protein levels sufficient for its function.

\section{Piwi cDNA partially rescues transposon derepression caused by EJC knockdown}

After determining that the predominant defect observed during EJC loss is in the splicing and subsequent accumulation of Piwi, we asked whether we could restore transposon regulation by expressing Piwi from a cDNA template. We expressed integrated, inducible Piwi-GFP cDNA and a control cDNA that lacks a nuclear localization signal and produces a cytoplasmic protein in vivo (Fig. 5A; Sienski et al. 2012). We expressed these constructs in somatic cells together with dsRNA targeting armitage (armi), a piRNA component that is post-transcriptionally required for Piwi nuclear localization (Haase et al. 2010; Olivieri et al. 2010; Saito et al. 2010). As expected, even wild-type Piwi is incapable of entering the nucleus during armi depletion (Fig. 5B). In contrast, Piwi produced from this cDNA localized properly to the nucleus in the absence of RnpS1, indicating that the EJC does not play a role in Piwi localization (Fig. 5B).

To examine whether reconstitution of Piwi is sufficient to restore transposon regulation in the absence of RnpS1, we examined the steady-state levels of several transposable elements. Using qRT-PCR, we detected a somatic restoration of piwi transcript levels from cDNA despite persistent depletion of RnpS1 (Fig. 5C). We then assessed transposon levels and found a partial suppression of $Z A M$ transcription and, to a lesser extent, Blood (Fig. 5C). We used RNA FISH recognizing $Z A M$ transcripts to test whether piwi cDNA could also rescue the effects of loss of a core EJC subunit. We observed a marked restoration of $Z A M$ silencing in ovaries with SKD of tsu (Supplemental Fig. S7A). We noticed that the cDNA constructs were expressed in a variegated pattern in follicle cells (Fig. 5B; Supplemental Fig. S7B), potentially preventing a more robust rescue of transposon silencing. Taken together, we conclude that Piwi is a critical effector of the EJC in preventing transposon mobilization.

\section{RnpS1-dependent intron removal requires splicing of flanking introns}

To gather more insight into the molecular mechanism by which the EJC regulates piwi splicing, we designed several minigene constructs containing portions of the piwi locus encompassing the EJC target intron (intron 4) and transfected them into Drosophila embryonic Schneider $\left(\mathrm{S}_{2} \mathrm{R}^{+}\right)$ cells, which have no detectable endogenous piwi. We found that expression of a short genomic construct from exon 3 to exon 6 (construct-1) recapitulated the RnpS1 dependence of intron 4 removal observed in the gonads (Fig. 6A, B, $\mathrm{B}^{\prime}$ ). While intron 4 was almost completely spliced in construct-1, its retention was increased by $20 \%$ upon RnpS1 depletion (Fig. 6B, B'). Interestingly, we observed that removing the flanking introns from this construct had a severe impact on intron 4 excision under control conditions, and this was not aggravated by RnpS1 depletion (Fig. 6B, $\mathrm{B}^{\prime}$, construct-2). We next assessed the relative importance of the two flanking introns. We found that removing only intron 5 had a strong effect on intron 4 removal (50\% retention), which was further exacerbated by depletion of RnpS1 (85\% retention) (Fig. 6B,B', construct-3). Conversely, removing only intron 3 led to a minor effect on intron 4 splicing (20\% retention), but this defect was strongly aggravated by RnpS1 depletion (70\% retention) (Fig. 6B, $\mathrm{B}^{\prime}$, construct-4). Altogether, these results show that both flanking introns are required for correct splicing of intron 4, with intron 5 having a greater impact. Furthermore, both flanking introns exert their effect through RnpS1.

The positive effect of the flanking introns could be due to either their cis-regulatory sequences or their splicing per se. To test whether their splicing was important, we generated point mutations in the $5^{\prime}$ or $3^{\prime}$ splice sites $\left(5^{\prime}\right.$ ss or $3^{\prime}$ ss) of intron 3 and examined the splicing of intron 4 . Strikingly, prevention of intron 3 splicing completely inhibited the splicing of the downstream intron (Fig. 6C, $\mathrm{C}^{\prime}$ ). Furthermore, knocking down RnpS1 did not aggravate this effect. A similar effect was observed when the 5'ss of intron 5 was mutated in construct-4. In this case, preventing intron 5 splicing leads to a complete inhibition of the splicing of the upstream intron (Fig. 6C, $\mathrm{C}^{\prime}$ ). Together, these results demonstrate that splicing of flanking introns is necessary to enable RnpS1 to promote splicing, likely via the deposition of the EJC at exon junctions.

\section{A weak PPT at the $3^{\prime}$ end of the retained intron confers RnpS1 dependence}

We wondered whether the splicing defect observed in RnpS1 knockdown was unique to piwi or more globally prevalent. To this end, we reanalyzed our RNA-seq data sets from RnpS1-depleted ovaries in search of transcripts 


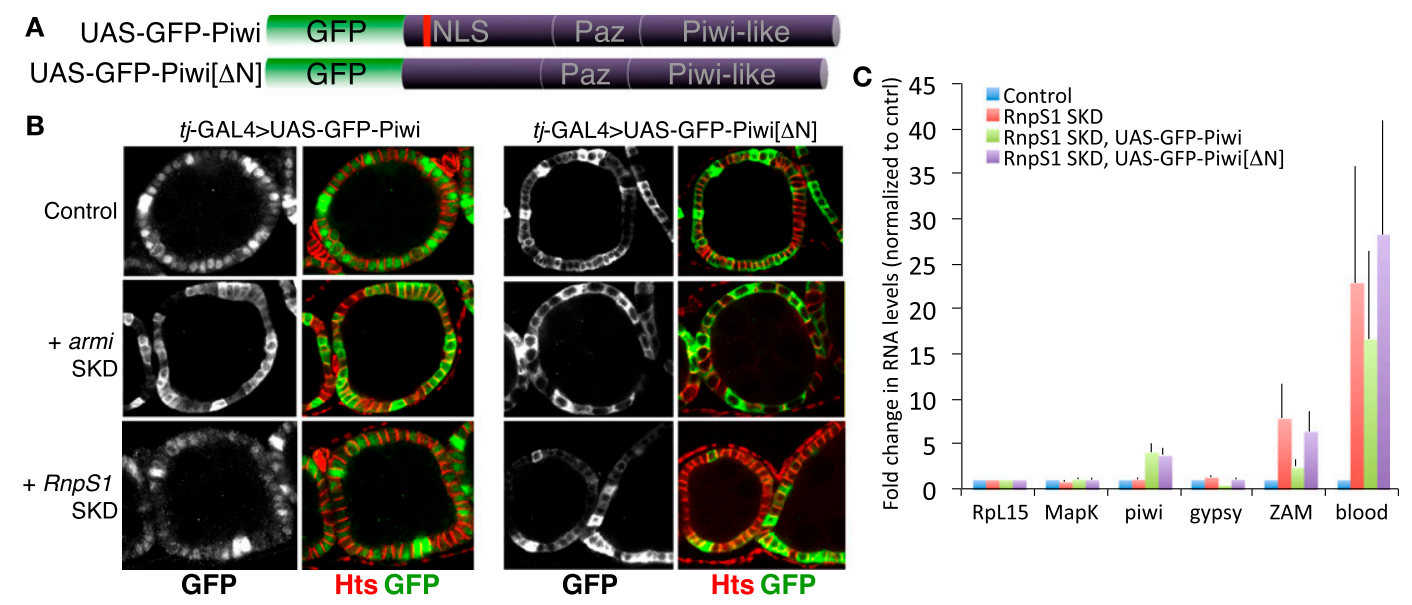

Figure 5. Expression of Piwi cDNA partially restores transposon up-regulation caused by EJC knockdown. (A) Schematic of UAS promoter-driven GFP-Piwi and GFP-Piwi with the nuclear localization signal removed to serve as a negative control. $(B)$ Somatic expression of Piwi constructs in control and armi or RnpS1 knockdown egg chambers stained for anti-Hts (red) and anti-GFP (green). (C) qRT-PCR of somatic transposons in RnpS1 SKD ovaries without and with the coexpression of Piwi constructs.

that showed signs of intron retention. Interestingly, we found that 33 transcripts showed a significant increase in intronic-derived reads, with some transcripts having multiple introns retained (Supplemental Table S1). Out of seven tested directly, six intron retention events were validated by qPCR (Supplemental Fig. S8).

To investigate the type of sequence elements able to generate RnpS1 dependence, we engineered several versions of the piwi minigene construct-3. We first asked whether the strength of the splice sites could explain the EJC dependency. Using the Berkeley Drosophila Genome Project (BDGP) splice site predictor software, we noticed that the 5'ss of intron 4 has a low score (0.31) compared with other 5 'ss of the piwi primary transcript. Therefore, we replaced the $5^{\prime}$ ss of intron 4 with the 5 'ss of the higher-scoring intron 2 . While this substitution improves the splicing efficiency of intron 4 , it does not relieve the requirement for RnpS1 (Fig. 7A), ruling out splice site strength as a main determinant of RnpS1 dependence. Next, we replaced the entire intron 4 with an intron of similar size from a tubulin transcript. Interestingly, this substitution completely rescued the splicing defect associated with the lack of RnpS1 (Fig. 7A). Loss of RnpS1 dependence was also observed when the endogenous 5 'ss of intron 4 was still present. This indicates that retention of the piwi intron is due to specific sequence elements that lie within the intron itself rather than binding of splicing inhibitors at flanking exons. In order to identify the minimal sequence that confers RnpS1 dependence, we reintroduced portions of the piwi intron into this construct (Fig. 7B,C). Interestingly, introducing only the last $100 \mathrm{nt}$ of piwi intron 4 was sufficient to alter splicing and reestablish RnpS1 dependence. This sequence is highly enriched in adenine in its last $30 \mathrm{nt}$, suggesting that the PPT of this intron is altered (Fig. 7D). To confirm this hypothesis, we specifically replaced this A-rich sequence with the last $30 \mathrm{nt}$ of the tubulin intron, which displayed a complete rescue of the splicing defect (Fig. 7B).
In order to investigate whether this sequence is sufficient to generate RnpS1 dependence, we engineered a minigene construct in which we inserted this minimal sequence into a heterologous intron derived from the $f t z$ transcription factor 1 (ftz-f1) gene. We selected intron 5 of $f t z-f 1$ because it is similar in size to intron 4 of piwi and does not require RnpS1 for its splicing (Fig. 7E; data not shown). Strikingly, we found that the replacement of its last $30 \mathrm{nt}$ with the A-rich sequence of the piwi intron led to a retention of $40 \%$, which is increased by $25 \%$ upon RnpS1 knockdown. This result demonstrates that the PPT of piwi intron 4 is sufficient to alter splicing and generate RnpS1 dependence. In addition, we found that, out of the 35 retained introns in RnpS1 knockdown, nine are enriched in adenine in their last $30 \mathrm{nt}$ (Supplemental Table S1), suggesting that weak PPTs may be a determinant of RnpS1 dependence in other introns, although additional features are likely to be involved.

Taken together, our results suggest that RnpS1 and the EJC play a general role in facilitating the removal of introns that are relatively difficult to splice. These data expand the catalog of regulatory functions of the EJC and, in this case, a subspecialization essential for the efficient maturation of diverse mRNAs in the cell.

\section{Discussion}

\section{Convergence of the EJC and piRNA pathways}

EJC subunit depletion causes a decrease in piRNA levels and Piwi function, leading to broad-scale transposon mobilization and demonstrating its essential role in the piRNA pathway. Consistent with our findings, EJC subunits have recently been identified as regulators of the piRNA pathway in genome-wide screens in Drosophila (Czech et al. 2013; Handler et al. 2013; Muerdter et al. 2013). We now demonstrate that the EJC controls the piRNA pathway by facilitating the splicing of a poorly 


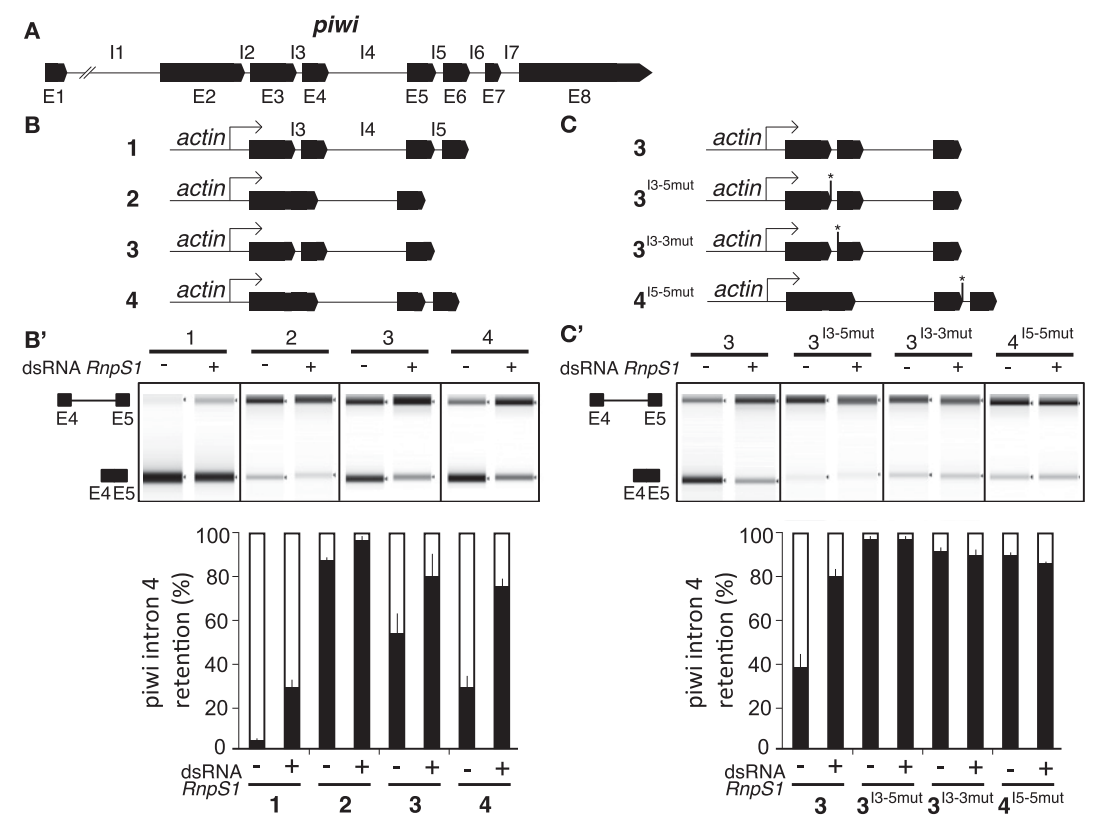

Figure 6. The EJC requires neighboring introns to support efficient splicing of the piwi fourth intron. (A) Schematic of the piwi genomic locus, with introns (I) and exons (E) marked accordingly. $(B, C)$ Various minigene constructs (1-4) containing the piwi fourth intron with or without flanking introns or splice site disruptions (asterisk). $\left(B^{\prime}, C^{\prime}\right.$, top) Capillary gels of RT-PCR with primers flanking intron 4 using extracts from control or RnpS1-depleted Drosophila S2R ${ }^{+}$cells. (Bottom) Graphs showing the ratio of spliced (white) versus unspliced (black) fourth intron.

structured intron within the piwi pre-mRNA. In the absence of the EJC, the unspliced piwi transcript is unable to support sufficient Piwi protein production to maintain transposon regulation in the gonads. This indicates an additional role for splicing factors in the piRNA pathway, as it was previously shown that the splicing and export factor UAP56 is implicated in the processing of dual-strand piRNA cluster transcripts (Zhang et al. 2012). The EJC may also regulate AGO3, as we observed a moderate decrease in transcript levels on RnpS1 knockdown (Supplemental Fig. S5), an effect on AGO3 localization in mago mutants (Supplemental Fig. S2E), and partial intron retention (Supplemental Fig. S6). However, in both cases, we still detected piRNA ping-pong activity, indicating that AGO3 maintains enzymatic function upon depletion of the EJC.

\section{A novel function for the pre-EJC and splicing factor RnpS1}

The EJC is recruited to mRNAs concomitant with splicing and remains strongly associated following export to the cytoplasm, where it can influence their subsequent fates. Several studies have recently challenged the view that the EJC serves only as a memory of the nuclear history of mRNAs and provided evidence for its involvement in the splicing process itself (Ashton-Beaucage et al. 2010; Roignant and Treisman 2010; Michelle et al. 2012). However, since EJC subunits are recruited only at a late step of the splicing reaction, just prior to exon ligation, it remained unclear how they could influence this process. Here we provide a mechanism by which the EJC regulates the splicing of the piwi transcript. We found that excision of the weak intron in the piwi transcript (intron 4) is facilitated by the splicing of strong adjacent introns, likely via the deposition of the EJC at neighboring splice junctions. In addition to the core pre-EJC, the EJC splicing subunit RnpS1 appears to be necessary to perform this function.

In vivo cooperation between introns for their processing has been previously observed, but the mechanism has remained unclear (Neel et al. 1993; Nesic and Maquat 1994; Romano et al. 2001). For instance, introns of the tumor necrosis factor $\beta$ (TNF $\beta$ ) transcript are spliced more efficiently in HeLa cells when upstream introns are still present (Neel et al. 1993). Similarly, upstream introns influence the efficiency of removal of the final intron of the human triosephosphate isomerase (TPI) transcript (Nesic and Maquat 1994). Importantly, in both cases, mutating the splice sites of the upstream introns abolishes their enhancing effect, indicating that their splicing per se is important. It has been proposed that the presence or absence of upstream introns can confer different secondary transcript structures, potentially influencing the efficiency of the splicing reaction (Tomizawa and Itoh 1981; Wong and Polisky 1985; Watakabe et al. 1989; Clouet d'Orval et al. 1991). In light of our results, we favor the hypothesis that deposition of the EJC at adjacent splice junctions could explain the positive influence of upstream introns.

Although some studies provided evidence that intron excision follows a $5^{\prime}$-to-3' polarity established during transcription (Wetterberg et al. 1996; Pandya-Jones and Black 2009), our data clearly show that this is not a strict rule. In the case of the piwi transcript, not only does third intron splicing influence the removal of the fourth intron, but the splicing of intron 5 appears absolutely required for efficient splicing of the upstream intron (4). These results are consistent with recent genome-wide studies in Drosophila demonstrating that first introns are generally less efficiently cotranscriptionally spliced than subsequent introns (Khodor et al. 2011). As the excision of these introns is kinetically delayed, it would be interesting to test whether the EJC also facilitates their processing. 
A
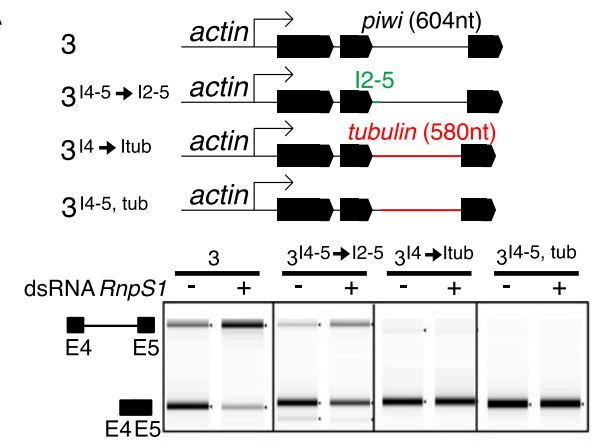

$\mathbf{B}$
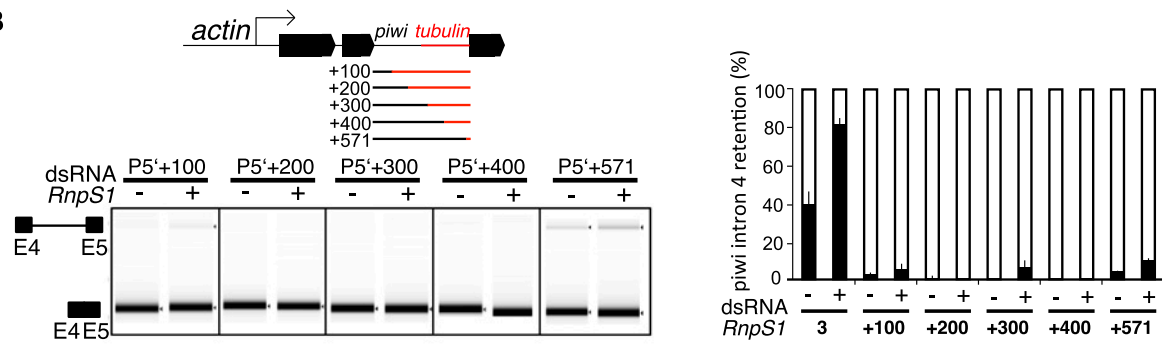

C
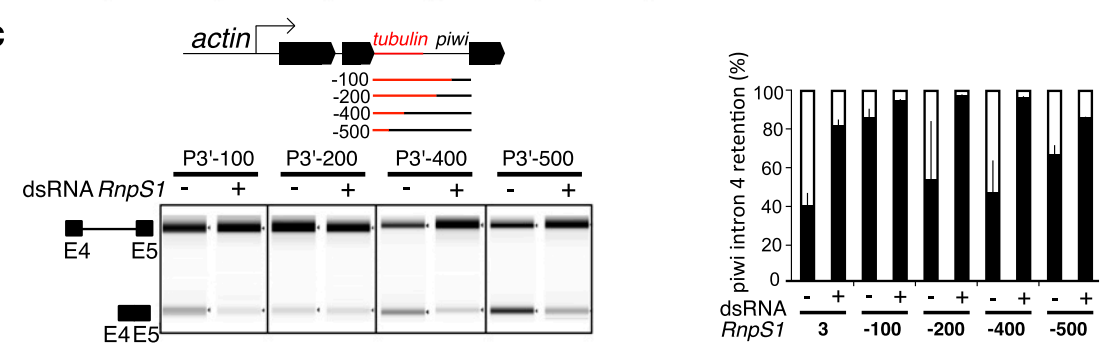

D
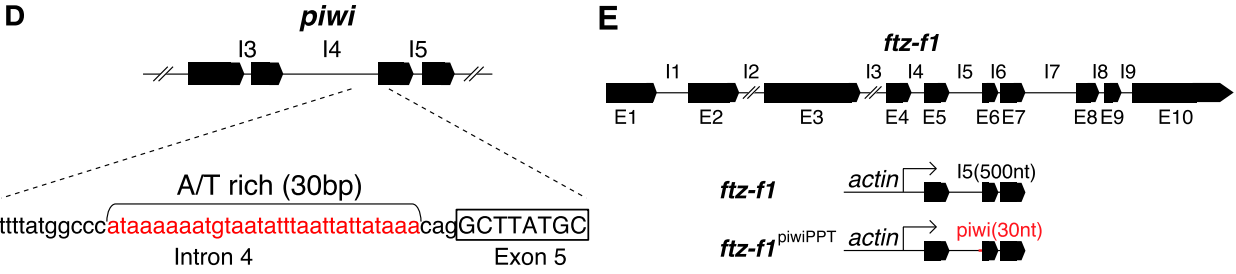

$\mathbf{F}$
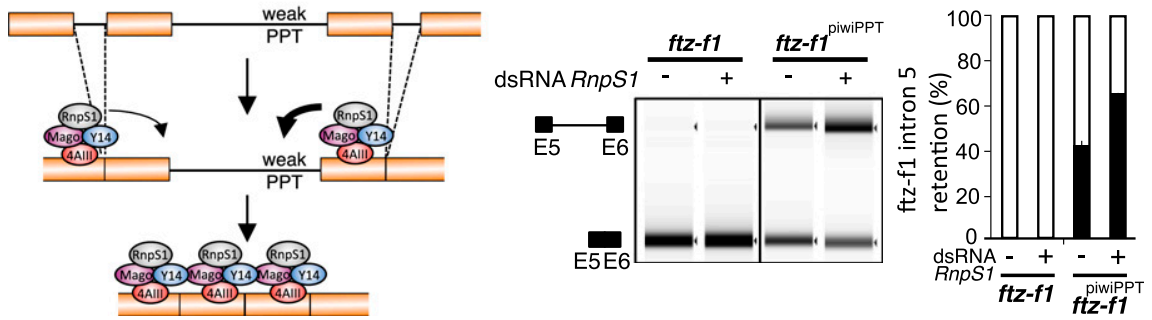

Figure 7. An abnormal PPT in the fourth intron of piwi confers sensitivity to the EJC. $(A-C)$ Diagrams of minigene constructs replacing the piwi fourth intron 5'ss with that of the piwi second intron (green) or portions of the fourth intron with the tubulin intron (red). Capillary gels and graphical depictions of qRT-PCR of minigene constructs with and without RnpS1 knockdown in Drosophila $\mathrm{S}^{2} \mathrm{R}^{+}$cells showing the ratio of spliced (white) versus unspliced (black) fourth intron. (D) Portrayal of the A/T-rich region (red) adjacent to the piwi fourth intron splice acceptor. $(E)$ Minigene construct diagrams, capillary gels, and graphical depictions of splicing of the $f t z-f 1$ fifth intron locus. Both the wild-type intron 5 and one swapped with the piwi PPT (red) were tested. (F) Model showing the pre-EJC and RnpS1 acting at flanking exon junctions to rescue inefficient splicing of the piwi fourth intron.

In a previous study, we had shown that many genes expressed from heterochromatic loci, including $M A P K$, are dependent on the pre-EJC for their splicing (Roignant and Treisman 2010). These genes are embedded in a highly compact chromatin structure and often contain remark- ably long introns occupied by a high density of repetitive elements. An accompanying study presented evidence that many transcripts containing large introns exhibit exon-skipping events upon pre-EJC knockdown (AshtonBeaucage et al. 2010). This is in stark contrast to piwi, which 
is expressed from a euchromatic domain, contains relatively small introns, and shows intron retention in the absence of the pre-EJC. Despite these differences, we found that its first and fourth introns, which are both dependent on the EJC for their faithful splicing, contain transposable element fragments. While these fragments might influence the efficiency of splicing by stretching the size of the intron, their presence is not necessary to generate EJC dependence. We identified 41 euchromatic introns of a size similar to the piwi fourth and containing transposable elements. However, those introns do not require RnpS1 for their splicing (Supplemental Fig. S9). In contrast, this dependence is due to a small region within the retained intron that contains a highly degenerate PPT (Fig. 7D). Replacing this region with a canonical PPT from the tubulin intron completely rescues splicing and abolishes EJC dependence. Conversely, replacing the canonical PPT from the $f t z-f 1$ intron with the degenerate PPT from the piwi intron is sufficient to confer EJC dependence (Fig. 7E). Therefore, our results support a model in which deposition of the EJC at adjacent splice junctions brings RnpS1 in proximity to the weak intron such that it facilitates spliceosome function by circumventing the absence of a canonical PPT (Fig. 7F).

RnpS1 forms two mutually exclusive subcomplexes with additional EJC subunits-one termed apoptosis and splicing-associated protein (ASAP), and the other termed PSAP (Schwerk et al. 2003; Murachelli et al. 2012). They share the SAP18 and differ by their association with an apoptotic chromatin inducer in the nucleus (Acinus) for ASAP and Pinin for PSAP. Several functions have been attributed to these complexes in transcription, programmed cell death, and mRNA processing (Zhang et al. 1997; Mayeda et al. 1999; Sahara et al. 1999; Li et al. 2003; Schwerk et al. 2003; Sakashita et al. 2004; Joselin et al. 2006; Vucetic et al. 2008; Singh et al. 2010). Whether all of these functions are shared with EJC core components is not known, nor is the underlying mechanism dictating their specificity. Intriguingly, we observed that Acinus depletion, similarly to RnpS1 knockdown, strongly affects piwi splicing, while neither SAP18 nor Pinin show a detectable requirement (Fig. 3A,B). These results indicate a functional specificity not only between the two complexes but also within the ASAP complex.

To summarize, we describe a role for the EJC in maintaining genome integrity by preventing transposon mobilization in the Drosophila germline. This is accomplished through the regulation of piwi transcript splicing, uncovering a novel mechanism of EJC-based rescue of inefficient splicing. Given the broad conservation of the EJC and the extent to which it can influence splicing events, we envision an extensive role that will continue to be uncovered.

\section{Materials and methods}

\section{Drosophila stocks and genetics}

All experiments were performed at $25^{\circ} \mathrm{C}$ on standard medium. When applicable, $w^{1118}$ flies served as controls. The fly stocks used are listed in Supplemental Table S2. mago ${ }^{93 D}$ and $t s u^{\Delta 18}$ mutant clones in the ovaries were generated by crossing FRT42D, mago $^{93 D}$ or FRT42D, $t s u^{\Delta 18}$ males to FRT42D, ubi-GFP; hsFLP122 females. Larvae were heat-shocked for $1 \mathrm{~h}$ at $38.5^{\circ} \mathrm{C}$ in both the first and second instar.

\section{Immunohistochemistry and Western blot analysis}

Ovaries were dissected from 4- to 5-d-old flies into ice-cold PBS. Tissues were fixed in 5\% FA in PBS for 20 min, permeabilized in $1 \%$ Triton X-100 in PBS, blocked in $0.2 \%$ Triton X-100 containing $1 \%$ BSA in PBS, stained with primary antibody, washed, stained with secondary antibody, washed, and mounted in VectaShield with DAPI (Vector Laboratories). Images were captured using either a TCS-SP5 (Leica) or LSM 510 (Zeiss) confocal microscope.

Western blots were performed as previously described (Miura et al. 2006). Protein extracts were generated from ovaries lysed in ice-cold lysis buffer $(50 \mathrm{mM}$ Tris at $\mathrm{pH} 8,150 \mathrm{mM} \mathrm{NaCl}, 1 \%$ Triton $\mathrm{X}-100$, complete protease inhibitor cocktail [Roche], 5 mM EDTA, $5 \mathrm{mM} \mathrm{NaF}, 1 \mathrm{mM} \mathrm{Na}_{3} \mathrm{VO}_{4}, 0.1 \%$ SDS, $0.5 \%$ sodium deoxycholate).

Primary antibodies used are listed in Supplemental Table S2. Secondary antibodies were coupled to Alexa 488 (1:1000), Cy3 (1:200), Cy5 (1:500), and Alexa 647 (1:500) (Jackson ImmunoResearch).

\section{Measurement of RNA levels}

Total RNA was extracted from cells or ovaries using TRIzol (Life Technologies) and treated as described (Roignant and Treisman 2010). For qRT-PCR analysis, cDNA was generated and then assayed using a ViiA7 real-time PCR system (Applied Biosystems). Primer sequences are listed in Supplemental Table S3. For semiquantitative PCR analysis, cDNA was amplified using Phusion high-fidelity DNA polymerase (New England BioLabs).

\section{Mutagenesis}

Point mutation-containing primers were designed in sense and antisense orientations to generate mutant PCR fragments and were subsequently phosphorylated using T4 polynucleotide kinase (New England BioLabs). Mutant fragments were cloned into TOPO vectors (Life Technologies) and then amplified using Phusion high-fidelity DNA polymerase. Fragments were then digested with DpnI (New England BioLabs) and transformed into DH5 $\alpha$-competent cells (Life Technologies).

\section{RNA FISH}

RNA FISH was performed using Stellaris probes as previously described (Raj et al. 2008) with slight modification. Forty-eight 20-nt Quasar 670-labeled probes were designed against the consensus ZAM retrotransposon, excluding LTR sequences.

\section{Cell culture, RNAi, and transfection}

$\mathrm{S} \mathrm{R}^{+}$cells were maintained in Schneider's medium supplemented with $10 \%$ fetal calf serum. dsRNAs were generated using the MEGAscript T7 (Life Technologies). S2R ${ }^{+}$cells were treated with $15 \mu \mathrm{g}$ of dsRNA, transfected $3 \mathrm{~d}$ afterward using Effectene (Qiagen), and retreated with $15 \mu \mathrm{g}$ of dsRNA. RNA and protein extractions were performed after $7 \mathrm{~d}$ in TRIzol or lysis buffer, respectively.

\section{RNA cloning and sequencing}

Total RNA from control and mago and RnpS1 GLKD and SKD ovaries were used to clone small RNA libraries as previously described (Brennecke et al. 2007). Additionally, 5' and 3' cloning adapters were modified with five randomized nucleotides flank- 
ing the small RNA to minimize ligation biases (Jayaprakash et al. 2011).

Strand-specific transcript profiling was performed on $2 \mu \mathrm{g}$ of ribosomal RNA-depleted total RNA from RpnS1 knockdown (GLKD and SKD), piwi ${ }^{1} /$ piwi $^{2}$, or control ovaries. All transcript and small RNA-seq data has been deposited at Gene Expression Omnibus (accession nos. GSE57710 and GSE59327).

\section{Computational analysis}

Raw small RNA sequences were demultiplexed, and randomized nucleotides were removed by trimming the first $5 \mathrm{nt}$ as well as the last five before the sequenced cloning adapter. Reads were then mapped to the Drosophila genome and annotated features, including miRNAs and transposons, as previously described (Brennecke et al. 2007). Ping-Pong analysis was performed as previously described (Brennecke et al. 2008). SKD and GLKD libraries were normalized to reads derived from the $42 \mathrm{AB}$ or flamenco piRNA clusters, respectively (Preall et al. 2012).

Raw RNA-seq data were demultiplexed, and the first $7 \mathrm{nt}$ were trimmed because of low sequencing quality. Reads were then mapped against the Drosophila genome BDGP5 (ensemble release 73). TopHat2 (Kim et al. 2013) and bowtie2 (Langmead and Salzberg 2012) were used to map, allowing two mismatches. Tags were assigned to features using HTSeq-count (http://wwwhuber.embl.de/users/anders/HTSeq/doc/overview.html), and differential gene expression was determined using DESeq (Anders and Huber 2010). Differentially expressed genes were filtered using false discovery rate (FDR) 0.1.

Differential intron expression was determined using DEXSeq (Anders et al. 2012), version 1.8.0. Read counting was performed using HTSeq-count 0.5.3p9 (http://www-huber.embl.de/users/ anders/HTSeq/doc/overview.html) with custom Python scripts provided by the DEXSeq.

For transposon analysis, reads were mapped against the transposon consensus reference (FlyBase release FB2013.05) using bowtie2, and multimapping reads were excluded. Differential expression analysis was performed using DESeq and determined using FDR 0.1, and only transposons with average coverage greater than one read per kilobase per million (RPKM) and a fold change greater than two were considered.

\section{Acknowledgments}

We thank members of the Roignant laboratory for helpful discussions, Felipe Karam Teixeira and Tatjana Treck for assay design assistance, and Anna Lena Leifke for technical support. We thank Institute of Molecular Biology facilities for their support, laboratory members and Rene Ketting for critical reading of the manuscript, the Bloomington Drosophila Stock Center and the Vienna Drosophila Resource Center for fly strains, and the Developmental Studies Hybridoma Bank for antibodies. Part of this work was performed in the laboratory of Dr. Ruth Lehmann, with support from the Howard Hughes Medical Institute. C.D.M. is supported by a post-doctoral fellowship from the Helen Hay Whitney Foundation. This project was funded in part by grants CIG 334288 (Marie Curie) to J.-Y.R, 1R21HG007394-01 (National Institutes of Health) to R.S., and MCB 1051022 (National Science Foundation) and EY013777 (National Institutes of Health) to J.T.

\section{References}

Alexandrov A, Colognori D, Shu MD, Steitz JA. 2012. Human spliceosomal protein CWC22 plays a role in coupling splicing to exon junction complex deposition and nonsense-mediated decay. Proc Natl Acad Sci 109: 21313-21318.
Anders S, Huber W. 2010. Differential expression analysis for sequence count data. Genome Biol 11: R106.

Anders S, Reyes A, Huber W. 2012. Detecting differential usage of exons from RNA-seq data. Genome Res 22: 20082017.

Ashton-Beaucage D, Udell CM, Lavoie H, Baril C, Lefrancois M, Chagnon P, Gendron P, Caron-Lizotte O, Bonneil E, Thibault P, et al. 2010. The exon junction complex controls the splicing of MAPK and other long intron-containing transcripts in Drosophila. Cell 143: 251-262.

Ballut L, Marchadier B, Baguet A, Tomasetto C, Seraphin B, Le Hir H. 2005. The exon junction core complex is locked onto RNA by inhibition of eIF4AIII ATPase activity. Nat Struct Mol Biol 12: 861-869.

Baralle D, Lucassen A, Buratti E. 2009. Missed threads. The impact of pre-mRNA splicing defects on clinical practice. EMBO Rep 10: 810-816.

Barbosa I, Haque N, Fiorini F, Barrandon C, Tomasetto C, Blanchette M, Le Hir H. 2012. Human CWC22 escorts the helicase eIF4AIII to spliceosomes and promotes exon junction complex assembly. Nat Struct Mol Biol 19: 983-990.

Bono F, Gehring NH. 2011. Assembly, disassembly and recycling: the dynamics of exon junction complexes. RNA Biol 8: 24-29.

Bono F, Ebert J, Lorentzen E, Conti E. 2006. The crystal structure of the exon junction complex reveals how it maintains a stable grip on mRNA. Cell 126: 713-725.

Braunschweig U, Gueroussov S, Plocik AM, Graveley BR, Blencowe BJ. 2013. Dynamic integration of splicing within gene regulatory pathways. Cell 152: 1252-1269.

Brennecke J, Aravin AA, Stark A, Dus M, Kellis M, Sachidanandam R, Hannon GJ. 2007. Discrete small RNAgenerating loci as master regulators of transposon activity in Drosophila. Cell 128: 1089-1103.

Brennecke J, Malone CD, Aravin AA, Sachidanandam R, Stark A, Hannon GJ. 2008. An epigenetic role for maternally inherited piRNAs in transposon silencing. Science 322: 1387-1392.

Carmell MA, Xuan Z, Zhang MQ, Hannon GJ. 2002. The Argonaute family: tentacles that reach into RNAi, developmental control, stem cell maintenance, and tumorigenesis. Genes Dev 16: 2733-2742.

Clouet d'Orval B, d'Aubenton Carafa Y, Sirand-Pugnet P, Gallego M, Brody E, Marie J. 1991. RNA secondary structure repression of a muscle-specific exon in HeLa cell nuclear extracts. Science 252: 1823-1828.

Cox DN, Chao A, Baker J, Chang L, Qiao D, Lin H. 1998. A novel class of evolutionarily conserved genes defined by piwi are essential for stem cell self-renewal. Genes Dev 12: 3715-3727.

Cox DN, Chao A, Lin H. 2000. piwi encodes a nucleoplasmic factor whose activity modulates the number and division rate of germline stem cells. Development 127: 503-514.

Czech B, Preall JB, McGinn J, Hannon GJ. 2013. A transcriptomewide RNAi screen in the Drosophila ovary reveals factors of the germline piRNA pathway. Mol Cell 50: 749-761.

David CJ, Manley JL. 2010. Alternative pre-mRNA splicing regulation in cancer: pathways and programs unhinged. Genes Dev 24: 2343-2364.

De Conti L, Baralle M, Buratti E. 2013. Exon and intron definition in pre-mRNA splicing. Wiley Interdiscip Rev RNA 4: 49-60.

Gatfield D, Izaurralde E. 2002. REF1/Aly and the additional exon junction complex proteins are dispensable for nuclear mRNA export. J Cell Biol 159: 579-588.

Gehring NH, Lamprinaki S, Hentze MW, Kulozik AE. 2009. The hierarchy of exon-junction complex assembly by the spliceosome explains key features of mammalian nonsense-mediated mRNA decay. PLoS Biol 7: e1000120. 
Gunawardane LS, Saito K, Nishida KM, Miyoshi K, Kawamura Y, Nagami T, Siomi H, Siomi MC. 2007. A slicer-mediated mechanism for repeat-associated siRNA $5^{\prime}$ end formation in Drosophila. Science 315: 1587-1590.

Haase AD, Fenoglio S, Muerdter F, Guzzardo PM, Czech B, Pappin DJ, Chen C, Gordon A, Hannon GJ. 2010. Probing the initiation and effector phases of the somatic piRNA pathway in Drosophila. Genes Dev 24: 2499-2504.

Hachet O, Ephrussi A. 2001. Drosophila Y14 shuttles to the posterior of the oocyte and is required for oskar mRNA transport. Curr Biol 11: 1666-1674.

Handler D, Meixner K, Pizka M, Lauss K, Schmied C, Gruber FS, Brennecke J. 2013. The genetic makeup of the Drosophila piRNA pathway. Mol Cell 50: 762-777.

Haremaki T, Weinstein DC. 2012. Eif4a3 is required for accurate splicing of the Xenopus laevis ryanodine receptor pre-mRNA. Dev Biol 372: 103-110.

Harris AN, Macdonald PM. 2001. Aubergine encodes a Drosophila polar granule component required for pole cell formation and related to eIF2C. Development 128: 2823-2832.

Iannone C, Valcarcel J. 2013. Chromatin's thread to alternative splicing regulation. Chromosoma 122: 465-474.

Jayaprakash AD, Jabado O, Brown BD, Sachidanandam R. 2011 Identification and remediation of biases in the activity of RNA ligases in small-RNA deep sequencing. Nucleic Acids Res 39: e141.

Jin Z, Flynt AS, Lai EC. 2013. Drosophila piwi mutants exhibit germline stem cell tumors that are sustained by elevated Dpp signaling. Curr Biol 23: 1442-1448.

Joselin AP, Schulze-Osthoff K, Schwerk C. 2006. Loss of Acinus inhibits oligonucleosomal DNA fragmentation but not chromatin condensation during apoptosis. J Biol Chem 281: 1247512484.

Khodor YL, Rodriguez J, Abruzzi KC, Tang CH, Marr MT 2nd, Rosbash M. 2011. Nascent-seq indicates widespread cotranscriptional pre-mRNA splicing in Drosophila. Genes Dev 25: 2502-2512.

Kim D, Pertea G, Trapnell C, Pimentel H, Kelley R, Salzberg SL. 2013. TopHat2: accurate alignment of transcriptomes in the presence of insertions, deletions and gene fusions. Genome Biol 14: R36.

Klattenhoff C, Bratu DP, McGinnis-Schultz N, Koppetsch BS, Cook HA, Theurkauf WE. 2007. Drosophila rasiRNA pathway mutations disrupt embryonic axis specification through activation of an ATR/Chk2 DNA damage response. Dev Cell 12: $45-55$

Langmead B, Salzberg SL. 2012. Fast gapped-read alignment with Bowtie 2. Nat Methods 9: 357-359.

Le Hir H, Izaurralde E, Maquat LE, Moore MJ. 2000. The spliceosome deposits multiple proteins 20-24 nucleotides upstream of mRNA exon-exon junctions. EMBO J 19: 6860-6869.

Le Hir H, Gatfield D, Izaurralde E, Moore MJ. 2001. The exonexon junction complex provides a binding platform for factors involved in mRNA export and nonsense-mediated mRNA decay. EMBO I 20: 4987-4997.

Le Thomas A, Rogers AK, Webster A, Marinov GK, Liao SE, Perkins EM, Hur JK, Aravin AA, Toth KF. 2013. Piwi induces piRNA-guided transcriptional silencing and establishment of a repressive chromatin state. Genes Dev 27: 390-399.

Li C, Lin RI, Lai MC, Ouyang P, Tarn WY. 2003. Nuclear Pnn/DRS protein binds to spliced mRNPs and participates in mRNA processing and export via interaction with RNPS1. Mol Cell Biol 23: 7363-7376.

Lin H, Spradling AC. 1997. A novel group of pumilio mutations affects the asymmetric division of germline stem cells in the Drosophila ovary. Development 124: 2463-2476.
Long JC, Caceres JF. 2009. The SR protein family of splicing factors: master regulators of gene expression. Biochem J 417: $15-27$.

Luco RF, Allo M, Schor IE, Kornblihtt AR, Misteli T. 2011. Epigenetics in alternative pre-mRNA splicing. Cell 144: 16-26.

Malone CD, Brennecke J, Dus M, Stark A, McCombie WR, Sachidanandam R, Hannon GJ. 2009. Specialized piRNA pathways act in germline and somatic tissues of the Drosophila ovary. Cell 137: 522-535.

Mayeda A, Badolato J, Kobayashi R, Zhang MQ, Gardiner EM, Krainer AR. 1999. Purification and characterization of human RNPS1: a general activator of pre-mRNA splicing. EMBO J 18: 4560-4570.

Megosh HB, Cox DN, Campbell C, Lin H. 2006. The role of PIWI and the miRNA machinery in Drosophila germline determination. Curr Biol 16: 1884-1894.

Michelle L, Cloutier A, Toutant J, Shkreta L, Thibault P, Durand M, Garneau D, Gendron D, Lapointe E, Couture S, et al. 2012. Proteins associated with the exon junction complex also control the alternative splicing of apoptotic regulators. Mol Cell Biol 32: 954-967.

Micklem DR, Dasgupta R, Elliott H, Gergely F, Davidson C, Brand A, Gonzalez-Reyes A, St Johnston D. 1997. The mago nashi gene is required for the polarisation of the oocyte and the formation of perpendicular axes in Drosophila. Curr Biol 7: 468-478.

Miura GI, Buglino J, Alvarado D, Lemmon MA, Resh MD, Treisman JE. 2006. Palmitoylation of the EGFR ligand Spitz by Rasp increases Spitz activity by restricting its diffusion. Dev Cell 10: 167-176.

Mohr SE, Dillon ST, Boswell RE. 2001. The RNA-binding protein Tsunagi interacts with Mago Nashi to establish polarity and localize oskar mRNA during Drosophila oogenesis. Genes Dev 15: 2886-2899.

Muerdter F, Guzzardo PM, Gillis J, Luo Y, Yu Y, Chen C, Fekete R, Hannon GJ. 2013. A genome-wide RNAi screen draws a genetic framework for transposon control and primary piRNA biogenesis in Drosophila. Mol Cell 50: 736-748.

Murachelli AG, Ebert J, Basquin C, Le Hir H, Conti E. 2012. The structure of the ASAP core complex reveals the existence of a Pinin-containing PSAP complex. Nat Struct Mol Biol 19: 378386.

Nagao A, Mituyama T, Huang H, Chen D, Siomi MC, Siomi H. 2010. Biogenesis pathways of piRNAs loaded onto AGO3 in the Drosophila testis. RNA 16: 2503-2515.

Neel H, Weil D, Giansante C, Dautry F. 1993. In vivo cooperation between introns during pre-mRNA processing. Genes Dev 7: 2194-2205.

Nesic D, Maquat LE. 1994. Upstream introns influence the efficiency of final intron removal and RNA 3'-end formation. Genes Dev 8: 363-375.

Newmark PA, Mohr SE, Gong L, Boswell RE. 1997. mago nashi mediates the posterior follicle cell-to-oocyte signal to organize axis formation in Drosophila. Development 124: 3197-3207.

Nishida KM, Saito K, Mori T, Kawamura Y, Nagami-Okada T, Inagaki S, Siomi H, Siomi MC. 2007. Gene silencing mechanisms mediated by Aubergine piRNA complexes in Drosophila male gonad. RNA 13: 1911-1922.

Olivieri D, Sykora MM, Sachidanandam R, Mechtler K, Brennecke J. 2010. An in vivo RNAi assay identifies major genetic and cellular requirements for primary piRNA biogenesis in Drosophila. EMBO J 29: 3301-3317.

Olivieri D, Senti KA, Subramanian S, Sachidanandam R, Brennecke J. 2012. The cochaperone shutdown defines a group 
of biogenesis factors essential for all piRNA populations in Drosophila. Mol Cell 47: 954-969.

Orengo JP, Cooper TA. 2007. Alternative splicing in disease. Adv Exp Med Biol 623: 212-223.

Pandya-Jones A, Black DL. 2009. Co-transcriptional splicing of constitutive and alternative exons. RNA 15: 18961908.

Parma DH, Bennett PE Jr, Boswell RE. 2007. Mago Nashi and Tsunagi/Y14, respectively, regulate Drosophila germline stem cell differentiation and oocyte specification. Dev Biol 308: 507-519.

Preall JB, Czech B, Guzzardo PM, Muerdter F, Hannon GJ. 2012. shutdown is a component of the Drosophila piRNA biogenesis machinery. RNA 18: 1446-1457.

Raj A, van den Bogaard P, Rifkin SA, van Oudenaarden A, Tyagi S. 2008. Imaging individual mRNA molecules using multiple singly labeled probes. Nat Methods 5: 877-879.

Roignant JY, Treisman JE. 2010. Exon junction complex subunits are required to splice Drosophila MAP kinase, a large heterochromatic gene. Cell 143: 238-250.

Romano M, Marcucci R, Baralle FE. 2001. Splicing of constitutive upstream introns is essential for the recognition of intraexonic suboptimal splice sites in the thrombopoietin gene. Nucleic Acids Res 29: 886-894.

Rozhkov NV, Hammell M, Hannon GJ. 2013. Multiple roles for Piwi in silencing Drosophila transposons. Genes Dev 27: 400412.

Sahara S, Aoto M, Eguchi Y, Imamoto N, Yoneda Y, Tsujimoto Y. 1999. Acinus is a caspase-3-activated protein required for apoptotic chromatin condensation. Nature 401: 168-173.

Saito K, Ishizu H, Komai M, Kotani H, Kawamura Y, Nishida KM, Siomi H, Siomi MC. 2010. Roles for the Yb body components Armitage and $\mathrm{Yb}$ in primary piRNA biogenesis in Drosophila. Genes Dev 24: 2493-2498.

Sakashita E, Tatsumi S, Werner D, Endo H, Mayeda A. 2004. Human RNPS1 and its associated factors: a versatile alternative pre-mRNA splicing regulator in vivo. Mol Cell Biol 24: $1174-1187$.

Sarot E, Payen-Groschene G, Bucheton A, Pelisson A. 2004. Evidence for a piwi-dependent RNA silencing of the gypsy endogenous retrovirus by the Drosophila melanogaster flamenco gene. Genetics 166: 1313-1321.

Sauliere J, Murigneux V, Wang Z, Marquenet E, Barbosa I, Le Tonqueze O, Audic Y, Paillard L, Roest Crollius H, Le Hir H. 2012. CLIP-seq of eIF4AIII reveals transcriptome-wide mapping of the human exon junction complex. Nat Struct Mol Biol 19: 1124-1131.

Schwerk C, Prasad J, Degenhardt K, Erdjument-Bromage H, White E, Tempst P, Kidd VJ, Manley JL, Lahti JM, Reinberg D. 2003. ASAP, a novel protein complex involved in RNA processing and apoptosis. Mol Cell Biol 23: 2981-2990.

Senti KA, Brennecke J. 2010. The piRNA pathway: a fly's perspective on the guardian of the genome. Trends Genet 26: 499-509.

Shibuya T, Tange TO, Sonenberg N, Moore MJ. 2004. eIF4AIII binds spliced mRNA in the exon junction complex and is essential for nonsense-mediated decay. Nat Struct Mol Biol 11: 346-351.

Shiimori M, Inoue K, Sakamoto H. 2013. A specific set of exon junction complex subunits is required for the nuclear retention of unspliced RNAs in Caenorhabditis elegans. Mol Cell Biol 33: 444-456.

Sienski G, Donertas D, Brennecke J. 2012. Transcriptional silencing of transposons by Piwi and maelstrom and its impact on chromatin state and gene expression. Cell 151: 964-980.
Silver DL, Watkins-Chow DE, Schreck KC, Pierfelice TJ, Larson DM, Burnetti AJ, Liaw HJ, Myung K, Walsh CA, Gaiano N, et al. 2010. The exon junction complex component Magoh controls brain size by regulating neural stem cell division. Nat Neurosci 13: 551-558.

Silver DL, Leeds KE, Hwang HW, Miller EE, Pavan WJ. 2013. The EJC component Magoh regulates proliferation and expansion of neural crest-derived melanocytes. Dev Biol 375: 172-181.

Singh KK, Erkelenz S, Rattay S, Dehof AK, Hildebrandt A, Schulze-Osthoff K, Schaal H, Schwerk C. 2010. Human SAP18 mediates assembly of a splicing regulatory multiprotein complex via its ubiquitin-like fold. RNA 16: 2442-2454.

Singh G, Kucukural A, Cenik C, Leszyk JD, Shaffer SA, Weng Z, Moore MJ. 2012. The cellular EJC interactome reveals higher-order mRNP structure and an EJC-SR protein nexus. Cell 151: 750-764.

Srebrow A, Kornblihtt AR. 2006. The connection between splicing and cancer. J Cell Sci 119: 2635-2641.

Steckelberg AL, Boehm V, Gromadzka AM, Gehring NH. 2012. CWC22 connects pre-mRNA splicing and exon junction complex assembly. Cell Reports 2: 454-461.

Tange TO, Shibuya T, Jurica MS, Moore MJ. 2005. Biochemical analysis of the EJC reveals two new factors and a stable tetrameric protein core. RNA 11: 1869-1883.

Theurkauf WE, Klattenhoff C, Bratu DP, McGinnis-Schultz N, Koppetsch BS, Cook HA. 2006. rasiRNAs, DNA damage, and embryonic axis specification. Cold Spring Harb Symp Quant Biol 71: 171-180.

Tomizawa J, Itoh T. 1981. Plasmid ColE1 incompatibility determined by interaction of RNA I with primer transcript. Proc Natl Acad Sci 78: 6096-6100.

Vucetic Z, Zhang Z, Zhao J, Wang F, Soprano KJ, Soprano DR. 2008. Acinus- $S^{\prime}$ represses retinoic acid receptor (RAR)regulated gene expression through interaction with the $\mathrm{B}$ domains of RARs. Mol Cell Biol 28: 2549-2558.

Watakabe A, Inoue K, Sakamoto H, Shimura Y. 1989. A secondary structure at the $3^{\prime}$ splice site affects the in vitro splicing reaction of mouse immunoglobulin $\mu$ chain premRNAs. Nucleic Acids Res 17: 8159-8169.

Wetterberg I, Bauren G, Wieslander L. 1996. The intranuclear site of excision of each intron in Balbiani ring 3 pre-mRNA is influenced by the time remaining to transcription termination and different excision efficiencies for the various introns. RNA 2: 641-651.

Wilson JE, Connell JE, Macdonald PM. 1996. aubergine enhances oskar translation in the Drosophila ovary. Development 122: 1631-1639.

Wong EM, Polisky B. 1985. Alternative conformations of the ColE1 replication primer modulate its interaction with RNA I. Cell 42: 959-966.

Zhang Y, Iratni R, Erdjument-Bromage H, Tempst P, Reinberg D. 1997. Histone deacetylases and SAP18, a novel polypeptide, are components of a human Sin3 complex. Cell 89: 357-364.

Zhang F, Wang J, Xu J, Zhang Z, Koppetsch BS, Schultz N, Vreven T, Meignin C, Davis I, Zamore PD, et al. 2012. UAP56 couples piRNA clusters to the perinuclear transposon silencing machinery. Cell 151: 871-884. 


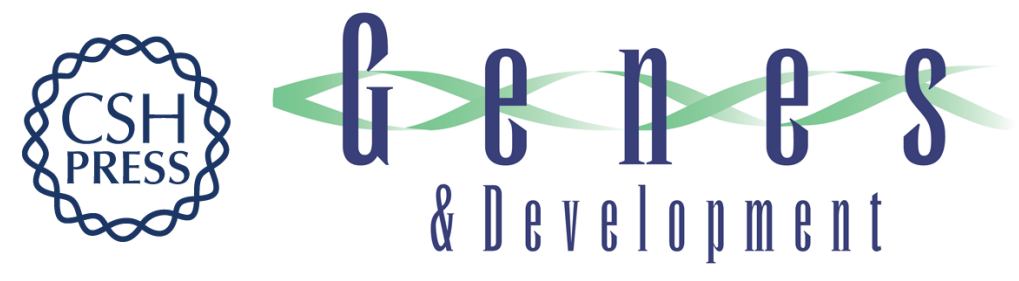

\section{The exon junction complex controls transposable element activity by ensuring faithful splicing of the piwi transcript}

Colin D. Malone, Claire Mestdagh, Junaid Akhtar, et al.

Genes Dev. 2014, 28: originally published online August 7, 2014

Access the most recent version at doi:10.1101/gad.245829.114

\section{Supplemental http://genesdev.cshlp.org/content/suppl/2014/08/04/gad.245829.114.DC1 \\ Material}

Related Content The exon junction complex is required for definition and excision of neighboring introns in Drosophila

Rippei Hayashi, Dominik Handler, David Ish-Horowicz, et al.

Genes Dev. August , 2014 28: 1772-1785

References This article cites 92 articles, 46 of which can be accessed free at:

http://genesdev.cshlp.org/content/28/16/1786.full.html\#ref-list-1

Articles cited in:

http://genesdev.cshlp.org/content/28/16/1786.full.html\#related-urls

Creative This article is distributed exclusively by Cold Spring Harbor Laboratory Press for the first Commons six months after the full-issue publication date (see

License http://genesdev.cshlp.org/site/misc/terms.xhtml). After six months, it is available under a Creative Commons License (Attribution-NonCommercial 4.0 International), as described at http://creativecommons.org/licenses/by-nc/4.0/.

Email Alerting Receive free email alerts when new articles cite this article - sign up in the box at the top Service right corner of the article or click here.

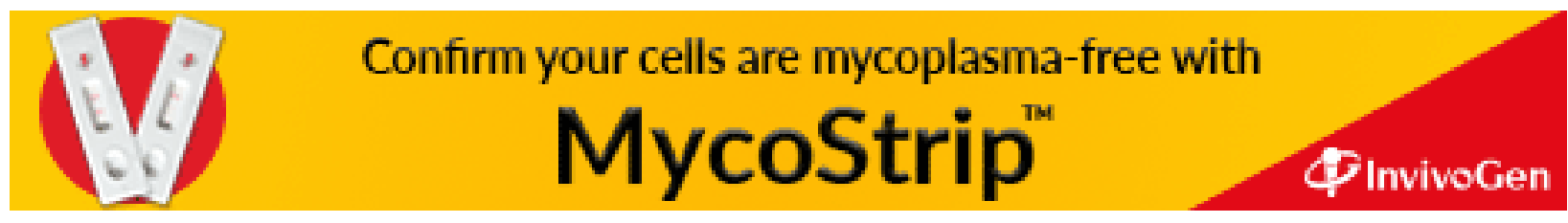

